Theories \& Applications, the International Edition

Printed Version: (ISSN 2090-5262)

Online Version: (ISSN 2090-5270)

July 2013, Volume 3, No. 2 Pages (89 - 100)

\title{
The Impact of the Isokinetic-Plyometric Training on the Development of Some Elements of Physical Fitness for Junior Basketball Players
}

\author{
Mohamed Abdul-hamid Belal*, Mohamed Zaki Younis Ghazzawi**
}

\begin{abstract}
The research aims to the development of some Physical abilities skills for junior basketball players less than 16 years old, through the identification of the effect of the proposed Training Program (Training with weights by combining between the Isokinetic- Plyometric Training) on some elements of physical fitness for basketball ( Explosive Power - Speed - Agility ). The researchers used experiment curriculum with two groups which has the nature of this research, where the application of the program using pre and post tests, Where the application of the proposed program used Isokinetic- plyometric method with the experimental group of 10 players, while the application of the Training with weights used Isotonic- plyometric method with the control Group of 10 players, the period of the program set for 12 weeks, was the unification of both sets of search exercises the same intensity and repeat, with the difference that the experimental group used Isokinetic device (device of mini-gym for Isokinetic contraction) while the control group used regular training by weights.

In addition to the plyometric exercises for both groups, and within the limits of conclusions reached, and from the analysis of data obtained to enable two researchers to use the method complex training (Isokinetic-plyometric) gave better results on the use of complex training method (Isotonic-plyometric) in the measurement of Explosive Power for legs and arms muscles, agility and speed transitional for junior basketball players. The training by using complex training method (Isokinetic- plyometric) led to improve vertical jump distance grew by $43.87 \%$, distance of throwing medicine ball by $11.79 \%$, improved agility by $19.13 \%$ and speed transition rate of 14.25 $\%$.
\end{abstract}

\section{Introduction}

$\mathrm{R}$ ecent years witnessed the scientific progress in the field of physical preparation for the players, and helped good knowledge scientific principles to the technological development in upgrading sports programs and specialized solutions to many problems related to this area.

The basketball game considers from the games that benefited greatly from the use of scientific methods to develop and progress, it is one of the most widespread games and is attracting a great deal of attention in many countries of the world,

\footnotetext{
* Assistant Professor, Games Training Department, Faculty of Sport Education for men, Alexandria University, Egypt.

** Researcher \& Physical loads scheme for the basketball teams at the Egyptian Ahli Club, Egypt.
}

from the excitement and fun.

One of the factors that helped the great progress in the field of basketball game in recent years was the considerable rise in the levels of training loads even arrived in size annual training to more than 1200 hours annually, which has become difficult to refrain from continuing increase training more than that, and that future progress will be linked to not only with increasing of training loads, but with choosing the most effective method of training and how to focus on the Installation Training doses that achieve better results, which means that the development will happen depend on the quality of the training and not to upgrade the loads, therefore, during the past years, many training methods achieved this goal. 
Mohamed Belal (2003) and Maffiuletti $\mathrm{Na}$ (2002) both used combine plyometric training and electrical stimulation to develop explosive power for legs muscles, and Santos, E., Janeira,M (2008) and Rahman et al. (2006) both used combine exercises with weights and plyometric training to develop the explosive power.

Ali Al Beik, Shaaban Ibrahim (1996), Mohamed Abdul Rahim, Emad Elddin Nofel (1993) and Abdul Aziz Al Nemr (1991) agree that the importance of explosive power as one physical quality that play an effective and vital role in the game of basketball.

Mohamed Belal (2003) sees that the basketball one of the games that includes many situations that requires from the player to be distinguished specially with explosive power besides the rest of the other elements of physical fitness, the basketball game legally begin with jump ball which requires the player to jump as high as he can and with high speed to pass the ball to the other player to start the game, while the position of basketball player changed from place to another quickly as performance requirements such as moving forward and backward, and then sudden move to receive the ball, dribbling, fast run to overcome to reach the target to shot and then follow-up in a state of defense or the attack case, all positions require strong legs are characterized by explosive power to help the players to perform their offensive and defensive requires.

In this regard, many researchers find how to develop the explosive power by using different training methods as one of the most important elements of physical fitness and sports in general, and basketball in particular.

Both Fleck \& Konter (1997) and George et al. (1995) defined that the mix between exercises with weights and plyometric training which they call it complex training, helps increasing the efficiency of the muscular nervous system, leading to the recruitment of the largest number of units in the muscle kinesthetic also increases the speed of nervous signals enclosed to the muscles.

Ebben (2002) defined the complex training that is a combination of exercises with weights followed by muscle group plyometric exercises for the same muscle group, which leads to produce an explosive muscle force in less time as possible.

Kostic (2008) confirmed that it is a mixture between exercises with weights, which is characterized by high intensity and explosive power and plyometric exercises that have an impact on the central nervous system, which leads to the recruitment of the largest possible number of units leads to nervous kinesthetic involvement of the largest possible number of muscle fiber, and this allows producing high power and quickly.

Ageloussis et al. (2003) mentioned that the complex training increase of secretion of enzymes which help to reach the neural signals in a faster way, and helps also on maximum output contraction of fast muscle.

Larry kenney et al. (2012) and Melainie C et al. (2011) both add that the types of muscle contractions are contractions used Isotonic, Isometric and Isokinetic, and considers the isokintic contractions one of the best types of muscle contractions as they develop the power over the course of the movement, thus, it involves the largest possible number of kinetic units.

Since the appearance of complex training and type of contractions used in exercises with weights which is isotonic contractions, Denise et al. (1985) finds that the Isotonic contractions is not the best types of contractions that allow maximum production of power on the full extent of the movement.

Abu Al Ela Abdul Fattah (2003) defined the Isokinetic contractions is the maximum muscle contraction which is quickly fixed through the full range of movement, and the word (ISO) similar or Equal username and (Kinetic) means the movement, hence, the designation of this type of muscle contractions came from the similarity with the movements that lead in sports activity.

Lorin Cartwright (2005) and Abul-Ela Abdul Fattah (2003) both emphasize that the Isokinetic programs better than the isotonic programs from the rate of achievement the power, and help in the development of performance skills, it is also less impact on the muscular pain and less exposed to injuries. 
It clears from the previous note the importance of the complex training which became one of the most usable method in developing of the explosive power in many Sports Activities generally and Basketball specifically, whereas the nature of some skills performances in basketball require combine between the maximum strength with maximum constriction speed of the muscle.

This is what helped the researchers to the application of the complex training using Isokinetic contractions instead of Isotonic contractions, for their impact on the maximum production of muscle power, this is appropriate with the nature of the performance movements in basketball. Jump, fast running and change direction need the players to have explosive power to perform these movements, Santos, E., Janeira,M (2008) and Mufti Ibrahim (2000) and Ali Al Beik (1992) agree that age (14-15) years is the stage which must upgrade power training programs by using special training appropriate with the activity practitioner.

\section{Aim of the Research}

The identification of the impact of the proposed training program (mix between training with weights by using Isokinetic and Plyometric training) on some of the physical abilities (Explosive power- Speed- Agility) for junior basketball players less than 16 years old.

\section{Previous Studies}

1. The study results of Santos, E., Janeira,M (2008) entitled "The impact of the complex training on the explosive power of junior basketball players", study aims to know the extent of the impact of complex training on the explosive power for junior basketball players, was the study on 25 basketball player from age 14-15 years were divided to two groups, the first control group included 10 players, and experimental 15 player, the results of the premeasurements were taken to the tribal jump distance vertical and at a distance from throw medical ball and then apply the complex training program for 10 weeks twice a week, to be re-tests and get the post- measurements, the results are in the interests of the experimental group, the researchers proved the effectiveness of complex training capacity in the development of muscular ability of arms and legs muscles for basketball player.

2. The study of Rahman et al. (2006) entitled the impact of the plyometric training, training by weights, and complex angular speed for legs muscles" , the study aims to compare the impact of three methods mentioned on the angular speed for legs muscles, the study included 48 college students were divided to 3 groups ( plyometric, weights, complex training), the test was in 6 weeks of training, and then measuring angular speed using ergometric bicycle, the study demonstrated the effectiveness of three methods in the development of angular speed for legs muscles with statistically interest for the complex training group.

3. The study of Mohammad Belal (2003) titled "The impact of the plyometric- electric training on the development of explosive power for legs and their relationship with the performance of the players of certain basic principles in basketball", study aimed to identify the impact of the plyometric- electric training on the development of explosive power for legs and their impact on improving some of the basic principles in basketball, The study was conducted on a sample selected basic intentional manner of Club's junior basketball players under 20 years old at Smouha Club, the sample included (20) players divided into two groups, where the first experimental group demonstrate the proposed training method (plyometricelectric) which is a mix between plyometricelectric training alerting to the muscles, while the second experimental group underwent through plyometric training using only, and continued the implementation of the training program for 12 a week by three training modules in the week, and through the Results and Discussion reached to the use of the suggested training method ((plyometricelectric) led to the development of explosive power for leg's muscle, where improved vertical jump distance by $23.47 \%$, and broad jump distance of $10.20 \%$.

4. The study of Matavulj D et al. (2001) entitled "The impact of the plyometric training on improved vertical jump for junior basketball players" , the study aimed to identify the impact of plyometric training on distance of vertical 
jump for junior basketball players, where researchers chose distinct group of basketball's youth were divided to three groups, The control group has special training system, while the other two groups went through specific training doses using plyometric training $50 \mathrm{~cm}$ for first group and $100 \mathrm{~cm}$ of second group, to identify the distance of vertical jump and maximum strength to the extenders knee muscles before and after experience, results of the study showed improvement in vertical jump distance of two sets of experimental research of the control group, where increased vertical jump distance of the group, used a distance of $50 \mathrm{~cm}$ to $4.5 \mathrm{~cm}$, while the group that used $100 \mathrm{~cm}$ increased $5.6 \mathrm{~cm}$ from pre test, and increased maximum force to the extenders knee muscles of both groups of plyometric training.

5. The study of Ioannis et al. (2000) entitled "A comparative study between the impact of the plyometric training, the training with weights and complex training on the distance of vertical jump muscles and power of legs' muscle " it aims to know the impact of the methods listed and comparability in vertical jump muscles and power of legs' muscle, The study was based on 41 players were divided to 4 groups (a control officer, the plyometric group, weights group and complex training group), was the work of pre test measurements for the 41 player and then underwent training program according to groups for 12 a week at a rate of 3 exercises per week then post test measurements, The results came positive for three methods but the best results were for the benefit of complex training group. And the researchers defined the importance of the use of complex training to develop muscle capacity.

6. The study of Amr Hassan Tammam (2000) entitled "The impact of a training program using plyometric exercises to develop the capacity and level of performance of muscle power and the level of shooting from jump for basketball players ", the study aimed to develop a training program using each of exercises with weights and the plyometric and identify the impact of this program on the rates of muscle power growth for different parts of the body, and their impact on rates of improvement in the performance level of shooting from jump. This research has been on a sample of (12) a player selected in the manner of intentional basketball players under 18 years at the Al-Mahalla club and registrars in Egyptian basketball Union 1999-2000 season and the researcher has used experimental curriculum design with one group and pre and post measurement, It has been applied the proposed program to the group for a period of (12) weeks by (3) training units a week, and the results of the research for the proposed training program using exercises with weights and plyometric led to the development of maximum force and muscle capacity for all parts of the body of research sample, also improved the performance of the shooting from jump.

7. The study of Islam Tawfiq (1998) titled: "The impact of a training with weights program and plyometric training on muscle power for basketball players ", the research aims to design a training program with weights and plyometric training, as well as to identify the impact of the proposed program to muscle power growth for basketball players, The researcher used experimental group included one sample of 14 players basketball who have never training with weights, and resulted that the use of training with weights exercises and plyometric training led to improvement in the growth rate of body muscles power, and increase muscle power for legs.

8. The study of Tarek Mohamed Shoukri (1996) titled : "study compared three proposed methods on the development of legs explosive power for basketball players", aimed to identify the impact of (weighs - jump with rope - Jump over the barriers) on the development of legs explosive power for basketball players 18-20 years, the research sample included (30) players from the basketball team of Al-Ahli club from 18-20 years and they have been divided into three experimental groups were have taken pre and post measurements of each of them, where trained each group, and continued the period of application of the program for (8) weeks by three training modules in the week. The results of the study that there is a positive impact when used the three methods in the development of legs explosive power, and did not achieve any of the three methods used superior from the other in the development of legs explosive power, and that training using ropes achieved 
the highest percentage in legs explosive power by $16.62 \%$ followed by training using barriers by $16.50 \%$ followed by using weighs training by $13.89 \%$.

\section{Research Statement}

Throughout the access to theoretical studies and analyses the results of previous studies and researches, the researchers could be drafting the following assumptions:

1. There are statistical differences between pre and post measurement for experimental group using complex training (Isokinetic- plyometric) in physical measurements under search for post measurement.

2. There are statistical differences between pre and post measurement for control group using complex training (Isotonic- plyometric) in physical measurements under search for post measurement.

3. There are statistical differences between experimental group using complex training (Isokinetic- plyometric) and control group using complex training (Isotonic- plyometric) in physical measurements under search for experimental group.

\section{Research Tools}

\section{Research Methodology}

The researchers used experiment curriculum with two groups, the curriculum has been used pre and post design of two sets of research groups, where the application of the proposed program method Isokinetic-plyometric on experimental group, while the application of the Training with weights Isotonic- plyometric on the control group.

\section{Research Population}

The sample was selected by intentional search from basketball players under (16) years in AlAhly Club of Egypt in Cairo and their number (20) players and registered in the Egyptian Basketball Fedration 2011/2012 season, and due to choose the researchers of this age to:

1. Growth in muscle power in this stage of age.

2. One of two researchers works in Al-Ahly club of Egypt as a supervisor of physical fitness of basketball teams.

3. The similar and previous studies conducted on the same stage of age.

The sample has been divided of (20) players in the randomly way to equal one experimental group (10) players and one control group (10) players, and has been this distribution centers according to the players in the stadium.

\section{The Time-Frame Area}

- The pre- evaluation measurements conducted from 1/04 -20/04/2011

- The pre- measurement conducted on 2 days 25-26/6/2011

- The research evaluation measurements conducted from 02/07/2011-25/9/2011

- The post measurement on 27-28/09/2011

\section{The Geographical Area}

The basic experiment research was conducted in the Gymnasium hall, as well as the legal basketball playground of Al-Ahly club of Egypt. 


\section{The Research Tools}

\section{Machines and Equipments}

1. Cones

2. Medical Scale for weight

3. Rasta meter for height

4. Stop Watch

5. Measurements tape $(\mathrm{cm})$

6. Chalk

7. Wall

8. Legal Basketballs

9. Medicine Balls (3 kg)

10. Leaper Mini Gym.

\section{The Advantage of the Machine}

1. Isokinetic contractions

2. Designed especially for controlling the performance speed

3. Changes resistors through the full range of movement

4. Maximum Muscle contraction with speed through the full range of movement

5 . Works with angular speed

6 . Board gives power indicator

7. Gives chance for training

8. Less tiredness for muscle and less injuries

9. Small size and easy to transport

\section{Tests and Measurements: Robin P (2007)}

1. Vertical Jump test $(\mathrm{cm})$

2. Throw Medicine ball ( $3 \mathrm{~kg}$ ) from sitting (m)

3. Agility test for basketball players (Running types around the forbidden area) (second)

4. Speed test running $3 / 4$ basketball $(21 \mathrm{~m})$. ( second)

The researchers has chosen this group of measurements which lead to the achievement of the objectives of the research and it is already used in the Arabic and foreign studies and researches, and had been designed its scientific transactions of sincerity and consistency and objectivity.

\section{Exploratory Studies}

The researchers studied (10) junior players under 16 years at $\mathrm{Al}$ Tawfiqiya club in the period from 1/4/2010 even-20/4/2010, with a view to identify:

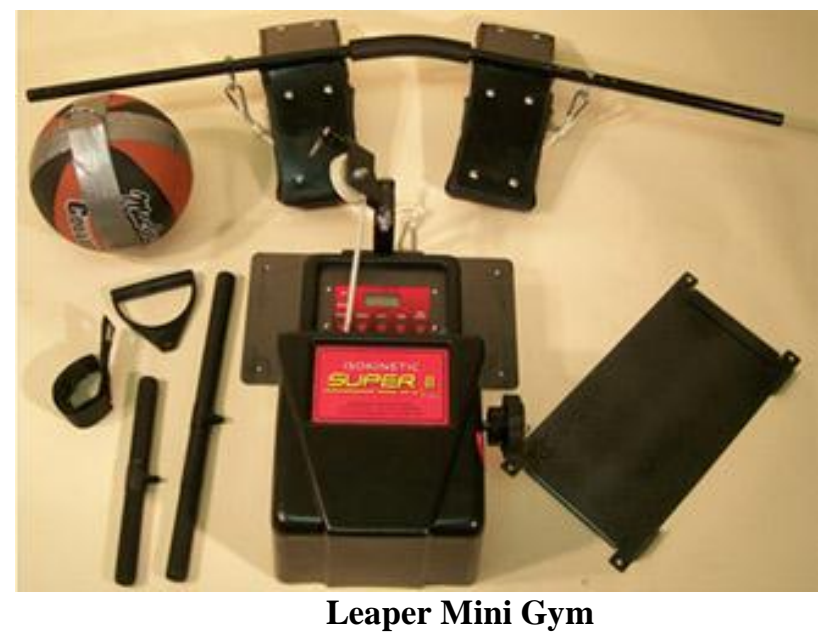

1. The quality of Isokinetic device.

2. Appropriateness of the device and how to perform the exercises.

3. Appropriateness of the exercises used in the program for the age performance and capacity, was reached following exercises, corresponding with the goals of the research:

\section{Exercises with Weights by Isotonic and Isokinetic}

1. Half Squat

2. Dead Lift

3. Bench Press

4. Shoulder Press

5. Cable Standing Decline Chest Press

\section{Plyometer Exercise}

1. Rim Jump

2. Half Squat Jump

3. Jump with throwing medicine ball on wall

4. Chest pass with medicine ball

5. Plyometric push up

\section{Basic Research Experience}

\section{The Pre Measurement}

The researchers conduct pre measurement on a sample search on $25-26 / 6 / 2011$, where the researchers install some of the experimental variables to ensure sincere impact experimental variable (training style complex IsokineticPlyometric) on the variable (some elements of fitness for junior basketball players), by using a set of measurements which already codified in previous studies and researches have proved its sincerity and constancy of objectivity as well as 
the relevance research sample, and the researchers adjust some of the factors related to the conduct of basic experience which can be summarized as follows:

1. The researchers supervise by themselves on the application of the research on the two groups.

2. Standardization of training days for each group together.

3. Measurements in the same system in the same way and the arrangement of each group.

\section{The Main Research Study}

Throughout the previous studies and references related to the subject of scientific research to enable the researchers to reach specific results represent the foundations of the program, which are:

1. Determine the period of program for the Experimental and control group for (12) twelve weeks.

- The experimental group trained by using (Isokinetic- Plyometric) training with the use of the leaper mini gym for Isokinetic contractions.

- The control group trained by using (Isotonic Plyometric) training.

2. Determine the period of the basic study from 2/7/2011 until 25/9/2011, and has been the implementation of the basic study during the period of preparation and within the program year to the members of the sample.

3. Numbers of 3 units weekly with a total of 36 Training Unit.

4. Time of each training Unit (90-120) Minutes training module.
5. Selection of suggested Training Program content (Isokinetic- Plyometric) based on the analysis and study of training programs which used complex training method using (Isotonic Plyometric) and programs used training Isokinetic alone and plyometric alone.

6 . The program includes a group of plyometric resistances exercises are designated as essential to the muscles working in basketball.

7. The intensity ranging of the Isokinetic training exercises resistances or isotonic from $55-85 \%$, the plyometric exercises is the intensity of the simple and medium resistance and mix between plyometric training method resistances as complex method, which was confirmed by Avery F \& Wayne W (2009) and Steven J (2004) and Abdul Aziz Tiger and Nareman AlKhatib (2000).

8. Designed exercises of both sets of research group with the same intensity and size, with the difference that the experimental group used Isokinetic device and the control group devices use regular weights, in addition to the plyometric exercises for both groups.

9. The performance of exercises was as follows:

- The player does a group of exercises with weights (Isokinetic for experimental group and isotontic for control group) for specific muscle group

- Rest period.

- Followed by a direct plyometric exercises for the same muscle group

The training program is divided for both groups into three periods, as illustrated in the Table No.(1)

Table (1)

The codification of user training program both groups

\begin{tabular}{|c|c|c|c|c|c|}
\hline Training Period & Units No. & Strength & Repeat & Groups & Comfort times \\
\hline \multirow{2}{*}{$\begin{array}{l}\text { General Preparation } \\
\text { (3 weeks })\end{array}$} & $1-2-4-5-7-8$ & $65 \%$ & 12 & \multirow{2}{*}{3} & \multirow{2}{*}{$\begin{array}{l}60 \mathrm{sc} \text {. Between resistance } \\
\text { and plyometric } \\
120 \mathrm{Sc} \text {. Between groups }\end{array}$} \\
\hline & $3-6-9$ & $55 \%$ & 15 & & \\
\hline \multirow{2}{*}{$\begin{array}{c}\text { Private Preparation } \\
\text { (6 weeks) }\end{array}$} & $\begin{array}{c}10-11-13-14-16-17-19- \\
20-22-23-25-26 \\
\end{array}$ & $75 \%$ & 10 & \multirow{2}{*}{3} & \multirow{2}{*}{$\begin{array}{l}90 \text { Sc. Between resistance } \\
\text { and plyometric } \\
180 \text { Sc. Between groups }\end{array}$} \\
\hline & $12-15-18-21-24-27$ & $65 \%$ & 12 & & \\
\hline \multirow{2}{*}{$\begin{array}{l}\text { Before competition } \\
\text { (3 weeks) }\end{array}$} & $28-29-31-32-34-35$ & $85 \%$ & $6-8$ & \multirow{2}{*}{3} & \multirow{2}{*}{$\begin{array}{c}120 \mathrm{Sc} \text {. Between resistance } \\
\text { and plyometric } \\
240 \mathrm{Sc} \text {. Between groups }\end{array}$} \\
\hline & $30-33-36$ & $75 \%$ & $8-10$ & & \\
\hline
\end{tabular}


Figure (2)

Clearing the performance during 36 training Unit

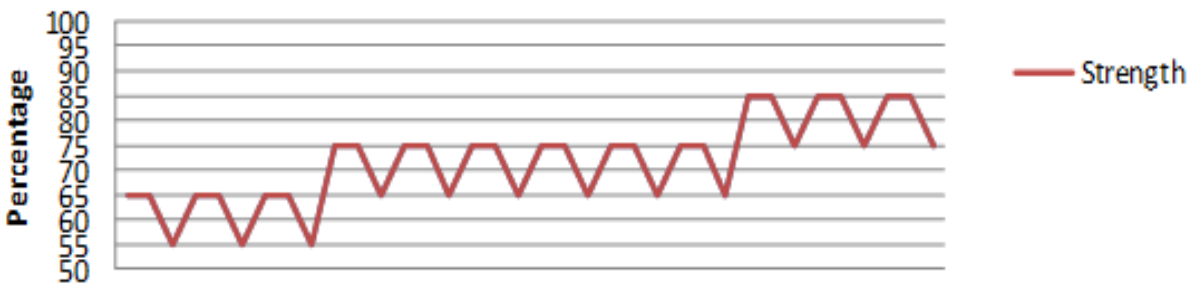

$\begin{array}{llllllllllllllllll}1 & 3 & 5 & 7 & 9 & 11 & 13 & 15 & 17 & 19 & 21 & 23 & 25 & 27 & 29 & 31 & 33 & 35\end{array}$

\section{Post Measurement}

The researchers did the post measurement tests on 27- 28 / 9 / 2011, the information has been unloaded and preparation of data statistical processors.

\section{Discussion}

Table (2)

Significance of differences between Experimental and control group in pre measurement.

\begin{tabular}{|c|c|c|c|c|c|c|}
\hline \multirow[b]{2}{*}{ Variable } & \multicolumn{2}{|c|}{ Experiment group } & \multicolumn{2}{|c|}{ Control group } & \multirow{2}{*}{$\begin{array}{c}\text { Average } \\
\text { differences }\end{array}$} & \multirow{2}{*}{$\begin{array}{c}\mathrm{T} \\
\text { Value }\end{array}$} \\
\hline & Average & $\begin{array}{l}\text { standard } \\
\text { deviation }\end{array}$ & Average & $\begin{array}{l}\text { standard } \\
\text { deviation }\end{array}$ & & \\
\hline Vertical Jump Test & 32.23 & 3.73 & 32.00 & 3.80 & 0.23 & 0.14 \\
\hline $\begin{array}{l}\text { Throw medicine ball from } \\
\text { sitting }\end{array}$ & 4.24 & 0.26 & 4.24 & 0.26 & 0.00 & 0.01 \\
\hline Special Agility Test & 15.21 & 0.60 & 15.21 & 0.64 & 0.00 & 0.00 \\
\hline $\begin{array}{c}\text { Running } 3 / 4 \text { basketball } \\
\text { court Test }\end{array}$ & 4.14 & 0.25 & 4.16 & 0.29 & -0.02 & 0.21 \\
\hline
\end{tabular}

The value of the " $T$ " at the level of moral $0.05=2.101$

It is clear from the table (2) the absence of differences in function between Experimental and control group statistically in all measurement variables, demonstrating the equalization of the two sets of search.

Table (3)

Significance of differences between pre and post measurement for Experimental group

\begin{tabular}{|c|c|c|c|c|c|c|c|}
\hline \multirow[b]{2}{*}{ Variable } & \multicolumn{2}{|c|}{ Pre measurement } & \multicolumn{2}{|c|}{ Post measurement } & \multirow[b]{2}{*}{$\begin{array}{c}\text { Average } \\
\text { differences }\end{array}$} & \multirow[b]{2}{*}{$\begin{array}{l}\text { Percentage of } \\
\text { Improvement }\end{array}$} & \multirow[b]{2}{*}{$\mathrm{T}$ Value } \\
\hline & Average & $\begin{array}{l}\text { standard } \\
\text { deviation }\end{array}$ & Average & $\begin{array}{l}\text { standard } \\
\text { deviation }\end{array}$ & & & \\
\hline Vertical Jump Test & 32.23 & 3.73 & 46.37 & 3.70 & 14.14 & $43.87 \%$ & $* 138.07$ \\
\hline $\begin{array}{l}\text { Throw medicine ball } \\
\text { from sitting }\end{array}$ & 4.24 & 0.26 & 4.74 & 0.15 & 0.50 & $11.79 \%$ & $12.86^{*}$ \\
\hline Special Agility Test & 15.21 & 0.60 & 12.30 & 0.48 & 2.91 & $19.13 \%$ & $32.50 *$ \\
\hline $\begin{array}{c}\text { Running } 3 / 4 \\
\text { basketball court Test }\end{array}$ & 4.14 & 0.25 & 3.55 & 0.13 & 0.59 & $14.25 \%$ & $12.31 *$ \\
\hline
\end{tabular}

The value of the " $T$ " at the level of moral $0.05=2.262$

It is clear from Table No. (3) The existence of differences statistically between pre and post measurement when the level of 0.05 in all physical variables search for post measurement.

It happened improvement in explosive power measurement for legs muscles (vertical jump) by $43.78 \%$ and improvement in explosive power measure for arms muscles (throw medicine ball) by $11.79 \%$, due to use the researchers of the proposed Training which is a mix between plyometric and Isokinetic training, both methods lead to the development of explosive power and combined between both methods helped improve explosive power, Matavulj D et al. (2001) The plyometric 
exercises are used to develop explosive power, which was confirmed also by study of Chiaching Liao (2011) and Amr Tammam (2000) and Islam Tawfiq (1998) that the plyometric training lead to development of explosive power, speed and agility, Abdul Fattah Abul-Ela (2003) emphasizes The Isokinetic training programs are the best programs of the Resistance and lead to improved explosive power, the researchers refer the improvement in the measurement of agility by improved 19.13 $\%$ and speed transitional improvement by 14.25 $\%$ to improve explosive power for legs muscles use the suggested training method helped to improve agility and speed transition, as confirmed by the results of the study of Mohammad Belal (2003) and Amr Tammam (2000) and Atef Rashad (1995) improve explosive power lead to improvement in the average of agility and speed transitional and improved the skills performance.

And the above achieves the first statement, that there are statistically differences between pre and post measurements for experimental group using complex training (Isokinetic- plyometric) in physical measurements under research for post measurement.

Table (4)

Significance of differences between pre and post measurement for Control group

\begin{tabular}{|c|c|c|c|c|c|c|c|}
\hline \multirow{2}{*}{ Variable } & \multicolumn{2}{|c|}{ Pre measurement } & \multicolumn{2}{|c|}{ Post measurement } & $\begin{array}{c}\text { Average } \\
\text { differences }\end{array}$ & $\begin{array}{c}\text { Percentage of } \\
\text { Improvement }\end{array}$ & T Value \\
\cline { 2 - 8 } & Average & $\begin{array}{c}\text { standard } \\
\text { deviation }\end{array}$ & Average & $\begin{array}{c}\text { standard } \\
\text { deviation }\end{array}$ & & & \\
\hline Vertical Jump Test & 32.00 & 3.80 & 42.83 & 3.72 & 10.83 & $33.84 \%$ & $66.87 *$ \\
\hline $\begin{array}{c}\text { Throw medicine ball } \\
\text { from sitting }\end{array}$ & 4.24 & 0.26 & 4.61 & 0.22 & 0.37 & $8.73 \%$ & $17.92 *$ \\
\hline Special Agility Test & 15.21 & 0.64 & 13.32 & 0.71 & 1.89 & $12.43 \%$ & $22.61 *$ \\
\hline $\begin{array}{c}\text { Running 3/4 } \\
\text { basketball court Test }\end{array}$ & 4.16 & 0.29 & 3.73 & 0.24 & 0.43 & $10.34 \%$ & $13.94 *$ \\
\hline
\end{tabular}

The value of the " $T$ " at the level of moral $0.05=2.262$

It is clear from Table No. (4) The existence of differences statistically between pre and post measurement when the level of 0.05 in all physical variables search for post measurement.

It happened improvement in explosive power measurement for legs muscles (vertical jump) by $33.84 \%$ and improvement in explosive power measure for arms muscles (throw medicine ball) by $17.92 \%$, due to use the researchers of the Complex Training which is a mix between plyometric and isotonic training, which studies confirmed that the development of explosive power and combined between both methods helped improve explosive power, Santos \& Janeira (2008), Rahman et al. (2005) and Ioannis et al. (2000), Table (4) clears that there is improvement in agility measurement by $12.43 \%$ and transitional speed by $10.34 \%$, which was confirmed also by the researchers when use the complex training method ( isotonic - plyometric) helped to development of explosive power for legs, and its effect on speed and agility, which was confirmed by Rahman et al. (2005) emphasizes The complex training helped to increase the distance of vertical jump and reduce the running time.

And the above achieves the second statement, that there are statistically differences between pre and post measurements for control group using complex training (isotonic - plyometric) in physical measurements under research for post measurement. 
Table (5)

Significance of differences between Experimental and Control group in post measurement

\begin{tabular}{|c|c|c|c|c|c|c|}
\hline \multirow[b]{2}{*}{ Variable } & \multicolumn{2}{|c|}{ Experiment group } & \multicolumn{2}{|c|}{ Control group } & \multirow{2}{*}{$\begin{array}{c}\text { Average } \\
\text { differences }\end{array}$} & \multirow{2}{*}{$\begin{array}{c}\mathrm{T} \\
\text { Value }\end{array}$} \\
\hline & Average & $\begin{array}{l}\text { standard } \\
\text { deviation }\end{array}$ & Average & $\begin{array}{l}\text { standard } \\
\text { deviation }\end{array}$ & & \\
\hline Vertical Jump Test & 46.37 & 3.70 & 42.83 & 3.72 & 3.54 & $2.13 *$ \\
\hline $\begin{array}{l}\text { Throw medicine ball from } \\
\text { sitting }\end{array}$ & 4.74 & 0.15 & 4.61 & 0.22 & 0.14 & $2.61 *$ \\
\hline Special Agility Test & 12.30 & 0.48 & 13.32 & 0.71 & 1.02 & $3.79 *$ \\
\hline $\begin{array}{c}\text { Running } 3 / 4 \text { basketball } \\
\text { court Test }\end{array}$ & 3.55 & 0.13 & 3.73 & 0.24 & 0.18 & $2.09 *$ \\
\hline
\end{tabular}

The value of the " $T$ " at the level of moral $0.05=2.101$

It is clear from Table No. (5) The existence of differences statistically between experimental and control group in all variables search for experimental group.

The value of $\mathrm{T}$ in measurement of the explosive power for legs muscle (vertical jump) by 2.13 and measurement of explosive power measure for arms muscles (throw medicine ball) by 2.61, $\mathrm{T}$ value for agility measurement 3.79 and transitional speed 2.09, due to use the researchers of the Complex Training (isokineticplyometric) for experimental group, while use complex training (plyometric and isotonic) training for control group, and the difference due to use the experimental group to the Leaper Mini Gym which helped to improve of the explosive power for legs and arms muscle in a better way of using isotonic methods which helped to improvement in agility and speed for experimental group, which was confirmed by Melainie C (2011) and Abuel Ella Abdul Fattah (2003) that the Isokinetic training better than isotonic training through the increase in the muscle power, speed and agility.

And the above achieves the third statement, that there are statistically differences between the experimental group by using complex training (isokinetic- plyometric) and control group by using complex training (isotonic- plyometric) for experimental group.

\section{Conclusions}

Within the results reached from analysis of data obtained to enable the researchers to draw the following:

1. Using the complex training method (Isokinetic- plyometric) gave better results on the use of complex training method (Isotonic- plyometric) in the measurement of explosive power for legs and arms muscles, speed and agility for junior basketball players.

2. Training by using complex training method (Isokinetic- plyometric) led to improve vertical jump distance by $43.87 \%$, throwing medicine ball for distance of $11.79 \%$, and improved agility by $19.13 \%$, speed transition by $14.25 \%$.

3. Availability factors of safety and security when using training method (Isokineticplyometric) where no injuries to any of sample's members basketball players under 16 years.

\section{References}

1. Abul-Ela Abdul Fattah, Physiology and Sports Training, First edition, Dar Al Fikr Al Arabi, 2003. (p 224)

2. Islam Tawfiq Mohammed, Impact of a training program with weights and plyometricexercises on muscles ability for basketball players, unpublished Master thesis, Faculty of physical education for men, Alexandria University, 1998.

3. Tarek Mohamed Shoukri Al Qobtan, Compared study three proposed methods to the development of explosive power for basketball players, Science magazine, the College of Physical Education for men in Cairo, Helwan University, number twenty-fourth, October, 1996.

4. Atef Rashad Khalil, The impact of use deep jump training on physical abilities on some volleyball players, unpublished Master thesis, Faculty of physical education for men, Helwan University, 1995.

5. Abdul Aziz Ahmed Al Nemr, The impact of two training programs with weights on the 
muscles ability for basketball players, Arts and Sciences, vol. III, No. III, 1991. P 14

6. Abdul Aziz Ahmed Al Nemr, Nariman AlKhatib, Physical setup and training with weights on junior players, professors sports book, first edition, 2000.

7. Ali Fahmi Al Beik, The Fundamental preparation of Football and group games players, Al Tony printing press, 1992, P 31-32.

8. Ali Fahmi Al Beik and Shaaban Ibrahim Muhammad, Planning training in basketball, a facility of knowledge, First edition, 1996. P 11

9. Amr Hassan Tammam, The impact of a training program using plyometric exercises to develop the muscles capacity and the level of shooting performance from jumping for basketball players, Master's thesis, Faculty of physical education, Tanta University, 2000.

10. Mohammad Abdul Hamid Belal, The impact of the plyometric- electric training to the development of explosive power for legs and their relationship with players performance of certain basic principles in basketball, unpublished $\mathrm{PhD}$ thesis, Faculty of physical education for men, Alexandria University, 2003. P 9

11. Mohammed Abdul Rahim Ismail, Emad Al Deen Nofal, Power Speed distinctive and its relation with triple shooting for junior basketball players, theories and applications, no. 14, Alexandria, 1993. P 371

12. Mufti Ibrahim Hammad, Modern Sports Training, First Edition knowledge facility, 2006.

\section{3.}

Aggeloussis,N.,Kasimatis,P.,mavromatic,G.,Gar as, A, Effect of a sub maximal half squat warmup program on vertical jumping ability , Journal of strength and conditioning, 2003, p342-344

14. Avery Faigenbaum, Wayne Westcott, Youth Strength Training: Programs for Health, Fitness and Sport (Strength \& Power for Junior Athlete), Human Kinetics; 1 edition (August 18, 2009), p 108

15. Chia-ching Liao, Plyometric Training Effects on Power, Speed and Agility in 6th Grade Male Basketball Players, Master Program of Physical Education, Chinese University, 2011
16. Denise L. Wiksten, Carolyn Peters, The athletic trainers guide to strength and endurance training, 1985, p 86.

17. Ebben WP, Complex training a brief review, J sports Sci \& Med, 2002, P 42-46.

Fleck,S ., Konter,K, Complex training. Strength and Conditioning Journal, 1986, p20.

18. George A. Brooks, Thomas D. Fahey, Timothy G. White: Exercise Physiology, Human Bioenergetics and Its Applications, Edition: 2nd, 1995, p65

19. Ioannis; Athanasios Z; Leontsini D; Kyriakos N; Kostopoulos N; Buckenmeyer P, Evaluation of Plyometric Exercise training, Weight training and their combination on vertical Jumping performance and leg Strength , Strength and Conditioning Journal, Volume 14 , Issue 4, 2000.

20. Kostic M , Complex training in Basketball , Sport Science 1(2008), 1:70-72

21. Larry Kenney, Jack Wilmore, David Costill, Physiology of Sport and Exercise, Library of Congress cataloging in publication Data, 5th ed ,2012, page 37.

22. Lorin Cartwright, William A. Pitney : Fundamentals Of Athletic Training, Human Kinetics. Copyright. , 2005, p 191

23. Maffiuletti NA, Dugnani S, Folz M, Di Pierno E, Mauro F., Effect of combined electrostimulation and plyometric training on vertical jump height, Motricite, Faculte des Sciences du Sport de Dijon, Universite de Bourgogne, France Oct 2002.

24. Matavulj D, Kukolj M, Ugarkovic D, Tihanyi J, Jaric S, Effects of plyometric training on jumping performance in junior basketball players, Research center, Faculty for physical culture , Belgrade, Yugoslavia, The Journal of Sports Medicine and Physical Fitness [2001, 41(2):159-164].

25. Melainie C, Steve S, Dennis Hl, Clinical Exercise, Elsevier Australia. Copyright. 2011, p 113-116

26. Rahman Rahimi, Parvin Arshadi, Naser Behpur,Saeed Sadeghi Boroujerdi, Mohammad Rahimi, Evaluation of Plyometrics, Weigth training and their combination on angular 
velocity, Physical Education and Sport Vol. 4, No1, 2006, pp. 1 - 8

27. Robin Pound, National Basketball Conditioning Coaches Association, Complete Conditioning for Basketball, Human Kinetics. Copyright. 2007, p 153

28. Santos,E., Janeira,M, Effects of Complex training on explosive strength in adolescent male basketball players, Strength and Conditioning Journal, Volume 22 - Issue 3 , 2008.

29. Steven J. Fleck, William J. Kraemer. Designing Resistance Training Programs, Human Kinetics. Copyright, 2004, p 46 